\title{
Maintenance Electroconvulsive Therapy For COMORBID PharmaCOTHERAPY-REFRACTORY OBSESSIVE-COMPULSIVE AND SCHIZOAFFECTIVE DisORDER
}

\author{
F. Hanisch ${ }^{1,2}$, J. Friedemann ${ }^{1}$, J. Piro ${ }^{1}$, P. Gutmann ${ }^{1}$ \\ ${ }^{1}$ Klinik und Poliklinik für Psychiatrie, Psychotherapie und Psychosomatik, ${ }^{2}$ Klinik und Poliklinik für Neurologie, \\ Martin-Luther-Universität Halle-Wittenberg, Halle (Saale), Germany
}

\begin{abstract}
Objective: There is a high comorbidity of schizophrenia and obsessive-compulsory disorder (OCD) associated with more severe symptoms. Standard pharmacotherapy achieve symptom improvement in approximatly $60 \%$ only.

Results: We report about a 48-old women treated for depression which developed successively psychotic symptoms (ideas of reference, psychotic worries), negative symptoms (blunted affect, impoverished thinking, difficulties in planning), and obsessive-compulsive symptoms (mainly repeating rituals, avoidance behaviour, collecting and hoarding). She did not respond to combined treatment with neuroleptics and high dose selective serotonin re-uptake inhibitors. She acutely improved during a course of electroconvulsive therapy (ECT) and was maintained on outpatient ECTs fortnightly together with $12 \mathrm{mg}$ sertindol and $45 \mathrm{mg}$ mirtazapine for 42 weeks.

Conclusion: Maintenance ECT is not an approved therapy in OCD but might be an option in pharmacotherapy refractory cases of comorbid OCD and schizophrenic/schizoaffective disorder.
\end{abstract}

Key words: obsessive-compulsive disorder; schizophrenia; electroconvulsive therapy; atypical neuroleptics

\section{INTRODUCTION}

The frequency of obsessive and compulsive (OC) symptoms in patients with schizophrenia is ranging from $3.5 \%$ to $26 \%$ and is higher than in the general population of less than 3\%. Patients with comorbidity of schizophrenia and obsessive-compulsive disorder (OCD) were shown to have greater impairments in executive functions, vigilance, negative, and emotional discomfort symptoms than those patients without OC [1]. First line strategies in the treatment of OCD with high-dose selective serotonin re-uptake inhibitors (SSRI), venlafaxine, or clomipramine, and congnitive behavioural therapy achieve symptom improvement in approximatly $60 \%$ only. Up to date there are only a few single case reports about electroconvulsive therapy (ECT) for comorbid OCD and schizophrenia [2, 3]. We report about a patient successfully treated with maintenance ECT in comorbid OCD and unipolar schizoaffective disorder.

\section{CASE REPORT}

The now 48-year old caucasian female nurse had been in psychotherapeutic treatment for several years. She was admitted to hospital for the first time at the age of 46 for a severe depressive episode treated with mirtazapine $45 \mathrm{mg}$. During the following weeks the patient developed psychotic symptoms as psychotic worries (debasement of her personality), helplessness, and ideas of reference treated with $25 \mathrm{mg}$ olanzapine, than $1400 \mathrm{mg}$ quetiapine due to resistancy. Later on compulsive symptoms occurred (repeated checking; picking up and collecting waste). Both schizodepressive and compulsive symptoms were only partially remitting under treatment with fluvoxamine $150 \mathrm{mg}$ and clozapine $400 \mathrm{mg}$ at time of discharge. Negative symptoms as difficulties in scheduling the day and deficits in concentration, attention, and comprehension were persisiting. She was able to live independently, but could not return to her occupation.

Over the following months the patient's OC symptoms, mainly compulsions, were exacerbating and spreading. It included contamination obsessions (confined to toilets), checking compulsions (checking lockers and cooker several times, following other persons or cars), repeating rituals (passing door- and stairways several times or in a ritualised way, touching items several times as door handles and handshaking), hoarding/collecting compulsions (picking up things from the street including waste and dog excrements, and hoarding these items), and avoidance behaviour (restricted to toilets). Before readmission it used to take her up to 4 hours to leave the outpatients department or home [Y-BOCS (Yale-Brown Obsessive Compulsory Scale) score: 40, CGI (Clinical Global Impression) severity score: 4]. Anxiety, blunted affect, thinking disturbances, and impoverished thinking had increased. Psychotic symptoms (see above) were relapsing. PANSS (Negative and Negative Syndrome Scale) showed a T-score and percentile equal to 99th percentile for negative syndromes, general psychopathology, and the cluster activation and depression and equal to 65th percentile for anergia. Combinations of clozapine (up to $1000 \mathrm{mg}$ ) with amisulpride (400 mg), and antidepressants (sertraline $200 \mathrm{mg}$ ) for two months did not significantly improve OC and schizophrenic symptoms. 
After informed consent and discontinuation of all oral medication the patient underwent 10 unilateral ECT treatments administered twice a week with no side effects. There was an immediate effect after the first to two sessions leading to the short-term complete remission of OC. Maintenance ECT was necessary because follow-up after one month showed reoccurrence of OC and schizophrenic symptoms (YBOCS score: 25, CGI severity: 3, improvement: 5; PANSS T-scores equal to 96th percentile for depression, and T-scores slightly above average for general psychopathology and activation). Maintenance ECT once in a fortnight in combination with $12 \mathrm{mg}$ sertindol and $45 \mathrm{mg}$ mirtazapine resulted in stable remission for 42 weeks (Y-BOCS score: 6, CGI severity: 1; PANSS T-scores for all items within the average range), which allowed her to live independently at home but did not enable her to re-enter her previous job or to start any other occupation due to passivity, affect blunting, and some problems in problem solving.

\section{DisCUSSION}

There are only anecdotal reports of individual cases [2, 3[ and a few open trials with case series [4, 5[ with ECT in pharmacotherapy refractory OCD showing a reduction of $\mathrm{OC}$ symptoms and a remission from one to 12 months. As for other indications and as shown in our case, maintenance ECT might be necessary in refractory OCD $[6,7]$. However, neither a placebocontrolled (sham-controlled procedure) nor pharmacotherapy-controlled trial is available for ECT in OCD. ECT has not received the approval of Food and Drug Adinistration for the treatment of OCD.

More published data are available for ECT in schizophrenia [8] but scarcely for schizoaffective disorders. The evidence of a Cochrane review suggested that ECT is superior to placebo and medication alone in patients with drug-resistant schizophrenia especially when combined with antipsychotic drugs. However, this initial beneficial effect may not last beyond the short-term despite pharmacotherapy and maintenance ECT therapy might be necessary. Substantial improvement after ECT in schizophrenia patients treated with clozapine persisted beyond 4 months in only $22.7 \%$ [9].

It has been proposed that atypical antipsychotic drugs like risperdone and olanzapine are highly beneficial in augmentating the response to SSRIs for the treatment of OCD [10]. However, it has also been anaecdotecally reported that atypical neuroleptics (clozapine, olanzapine, riperidone), when given as monotherapy, have caused the symptoms of OCD to appear or to worsen [11]. In retrospective studies the number of newly occurring OCD under treatment with clozapine was given with $2.4 \%-21 \%$ and $\mathrm{did}$ emerge with other atypical antipsychotics (olanzapine, risperidone) in less than $2 \%$ [11]. In the present case we cannot rule out that the OC symptoms were induced and aggravated by atypical neuroleptics.

\section{REFERENCES}

1. Lysaker PH, Bryson GJ, Marks KA, Greig TC, Bell MD. Association of obsessions and compulsions in schizophrenia with neurocognition and negative symptoms. J Neuropsychiatry Clin Neurosci 2002; 14: 449-453

2. Lavin MR, Halligan P. ECT for comorbid obsessive-compulsive disorder and schizophrenia. Am J Psychiatry 1996; 153: $1652-3$

3. Chaves MP, Crippa JA, Morais SL, Zuardi AW. Electroconvulsive therapy for coexistant schizophrenia and obsessive-compulsive disorder. J Clin Psychiatry 2005; 66: $542-3$

4 Khanna S, Gangadhar BN, Sinha V, Rajendra PN, Channabasavanna SM. Electroconvulsive therapy in obsessive-compulsive disorder. Convuls Ther 1988; 4: 314320

5. Maletzky B, McFarland B, Burt A. Refractory obsessive compulsive disorder and ECT. Convuls Ther 1994; 10: 34-42

6. Husain MM, Lewis SF, Thornton WL. Maintainance ECT for refractory obsessive-compulsive disorder. Am J Psychiatry 1993; 150: 1899-1900

7. Rabheru K, Persad E. A review of continuation and maintainance electroconvulsive therapy. Can J Psychiatry1997; 42: 476-484

8. Tharyan P, Adams CE. Electroconvulsive therapy for schizophrenia. Cochrane Database of Systematic Reviews 2005, Issue 2. Art. No.: CD000076

9. Havaki-Kontaxaki BJ, Ferentinos PP, Kontaxakis VP, Paplos KG, Soldatos CR. Concurrent administration of clozapine and electroconvulsive therapy in clozapine-resistant schizophrenia. Clin Neuropharmacol 2006; 29: $52-6$

10. Degner D, Bleich S, Kornhuber J, Ruther E. Olanzapine treatment of obsessive-compulsive disorder. Can J Psychiatry 2000; 45:393

11. Mahendran R, Liew E, Subramaniam M. De novo emergence of obsessive-compulsive symptoms with atypical antipsychotics in asian patients with schizophrenia or schizoaffective disorder : a retrospective, cross-sectional study. J Clin Psychiatry 2007; 68: 542-545

Received: November 17, 2008 / Accepted: March 19, 2009

Address for correspondence:

F. Hanisch, MD

Klinik und Poliklinik für Neurologie

Martin-Luther-Universität Halle-Wittenberg

Ernst-Grube-Str. 40

06120 Halle (Saale)

Germany

Phone: $\quad+49345557$

Fax: $\quad+49345557$

E-mail: Frank.hanisch@medizin.uni-halle.de 